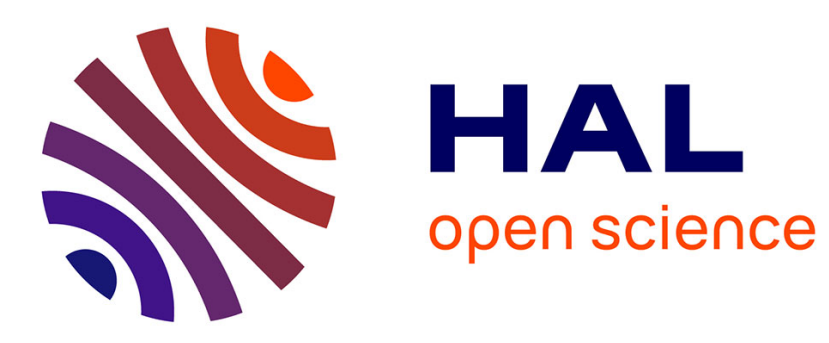

\title{
Evidence of dynamic postural control performance in parkour landing
}

Galo Maldonado, H Bitard, Bruno Watier, Philippe Souères

\section{To cite this version:}

Galo Maldonado, H Bitard, Bruno Watier, Philippe Souères. Evidence of dynamic postural control performance in parkour landing. Computer Methods in Biomechanics and Biomedical Engineering, 2015, 18 (S1), pp.1994-1995. 10.1080/10255842.2015.1069588 . hal-02002593

\section{HAL Id: hal-02002593 \\ https://hal.laas.fr/hal-02002593}

Submitted on 31 Jan 2019

HAL is a multi-disciplinary open access archive for the deposit and dissemination of scientific research documents, whether they are published or not. The documents may come from teaching and research institutions in France or abroad, or from public or private research centers.
L'archive ouverte pluridisciplinaire HAL, est destinée au dépôt et à la diffusion de documents scientifiques de niveau recherche, publiés ou non, émanant des établissements d'enseignement et de recherche français ou étrangers, des laboratoires publics ou privés. 


\title{
Evidence of dynamic postural control performance in parkour landing
}

\author{
G. Maldonado $^{\mathrm{ab} *}$, H. Bitard, B. Watier ${ }^{\mathrm{ab}}$, P. Soueres ${ }^{\mathrm{ac}}$ \\ ${ }^{a}$ CNRS, LAAS. 7 avenue du colonel Roche, F-31400 Toulouse, France \\ ${ }^{b}$ University of Toulouse, UPS, LAAS, F-31400 Toulouse \\ ${ }^{c}$ University of Toulouse, LAAS, F-31400 Toulouse
}

Keywords: postural control, landing, parkour, stability

\section{Introduction}

Postural control is a key component in many sports and daily live activities (Hrysomallis, 2011). Parkour is relatively a new discipline invented in France by David Belle and Sébastien Foucan in which practitioners have to overcome obstacles in the most efficient manner by exploiting human physical capabilities. Movements include climbing, vaulting, jumping and landing. There are two parkour landing techniques: precision and roll landing respectively. Precision technique consists in landing on the forefoot bending the knees to absorb impact without any varus-valgus of the knees and using the arms to counterbalance the movement (Figure 1B). The goal of the present study is to analyze dynamic postural control performance of parkour precision landings and to compare with regular toe-heel landings (Figure 1A) at two different heights. The analyzed parameters were: time to stabilization (TTS) (Colby, Hintermeister, Torry, \& Steadman, 1999), dynamical postural stability index (DPSI) (Wikstrom, Tillman, Smith, \& Borsa, 2005) and confidence ellipsoid surface of the center of pressure (CoP) displacement (Takagi, Fujimura, \& Suehiro, 1985). We hypothesize that parkour practitioners have better dynamical postural control performance in landings than regular since they utilize a more stable compensatory movement to counteract the impact reaction forces. We further hypothesize that TTS is less for parkour practitioners because they land in a pose where the center of mass is close to the center of the support polygon. Finally we hypothesize the landing height effect on stability is not significant for both populations.

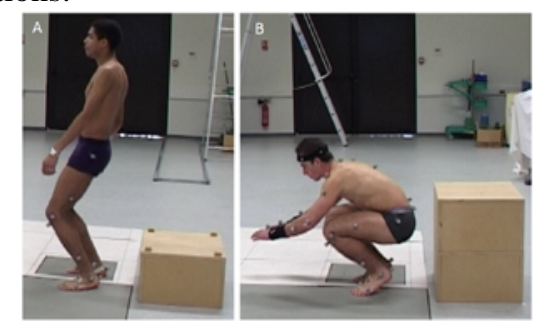

Figure 1 A) Untrained person B) Parkour practitioner

\section{Methods}

\subsection{Participants}

Six healthy male untrained participants $(21.3 \pm 3.9 \mathrm{y}$, $1.81 \pm 9.7 \mathrm{~m}, 74.5 \pm 7.5 \mathrm{~kg})$ and six healthy male parkour practitioners $(23.7 \pm 4 \mathrm{y}, 1.73 \pm 5.2 \mathrm{~m}, 61.2 \pm 6.1$ $\mathrm{kg}$ ) were recorded. Subject exclusion criterion was based on history of lower limb injuries/diseases that might affect landing biomechanics. All subjects signed informed consent forms prior experimentation as approved by local ethics committee.

\subsection{Landing Protocol}

For all trials, a $5 \mathrm{~min}$ session of warming up was required to subjects. Two heights were used to collect data: $30 \mathrm{~cm}$ and $60 \mathrm{~cm}$. For each height, 2 blocks of 3 trials were executed: one of familiarization and a second one of recording with $1 \mathrm{~min}$ of resting. Subjects were instructed to land barefoot using both feet simultaneously. Untrained subjects landed using toe-heel technique (Figure 1A) while parkour practitioners landed using parkour precision technique (Figure 1B).

\subsection{Instrumentation}

Two force plates (AMTI, Watertown, MA, USA) were embedded into the floor to record ground reaction forces (GRFs) and ground reaction moments (GRMs) sampling at $2000 \mathrm{~Hz}$.

\subsection{Data Analysis}

A MATLAB Release 2011b (The MathWorks, Inc., Natick, 60 Massachusetts, United States) program was written for data processing. GRFs were filtered with a low-pass Butterworth filter of 4th order applied in zero-phase with a cut-off frequency of $50 \mathrm{~Hz}$ based on a residual analysis. GRFs were normalized with body weight (BW). Initial contact was chosen as the instant when vertical GRF was greater than $30 \mathrm{~N}$. TTS of A-P axis was computed based on the work of (Colby 1999). DPSI in the anterior-posterior (A-P) axis was calculated based on (Wikstrom 2005) and normalized for each height. CoP was calculated from GRFs and GRMs.

\footnotetext{
* Corresponding author. Email: galo.maldonado@laas.fr
} 


\subsection{Statistical Analysis}

The average of 3 trials of all postural outcomes was calculated for each subject. CoP surface was computed using a confidence ellipsoid of 90\% (Takagi 1985) and normalized for each height. A bidirectional ANOVA was computed with heights and populations as the independent variables to compare the surfaces of the CoP ellipsoids and A-P GRFs. The total mean of A-P TTS, A-P DPSI and surface index was calculated in both populations.

\section{Results and discussion}
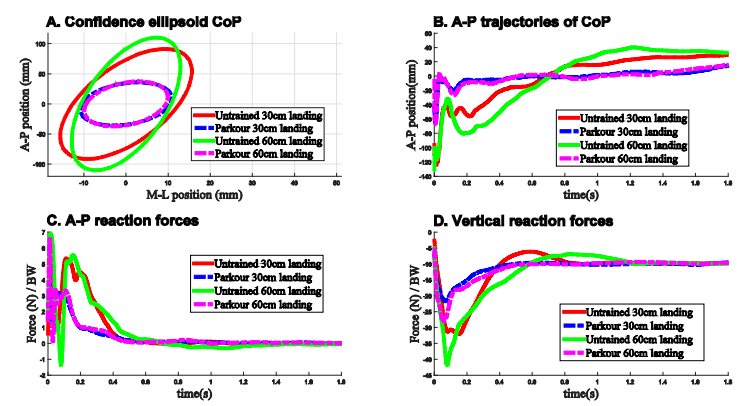

Figure 2 A) CoP confidence ellipsois B) A-P CoP trajectories C) A-P GRFs D) Vertical GRFs

\subsection{Surface of CoP}

Trial height did not affect the CoP surface. However parkour practitioners surface is 20 times lower than the CoP surface of untrained people (Table 1). In medial lateral (M-L) axis there is no significant difference of the CoP displacement while in the A-P axis the CoP of parkour practitioners is less displaced and remains more stable in time than in untrained people (Figure 2A,B). This reflects the fact that parkour technique offers a more stable compensatory movement to counteract the impact reaction forces.

\subsection{Time to stabilization TTS}

Differences on population type and trial height did not affect the A-P TTS value (Table 1). We believe that this is due to the fact that untrained people preactivate more muscles to counteract motion so that at the beginning phase of landing they are enough stiff to get stabilized faster and higher GRFs are generated. On the other hand, parkour practitioners performed a compliant landing generating less GRFs and an overdamped response (Figure 2D). A-P TTS is similar since they landed in a pose where the center of mass was closer to the center of the support polygon.

\subsection{Dynamic postural stability index DPSI}

A-P DPSI is not affect by the height but it changes depending on the population (Table 1). As A-P DPSI value is function of the A-P GRF, we believe that this result reflects the higher variation of A-P GRF in untrained subjects (Figure 2C) which is also due to the stiff landing they perform.

\begin{tabular}{|c|c|c|c|}
\cline { 2 - 4 } \multicolumn{1}{c|}{} & A-P & A-P & SURF \\
TTS(s) & DPSI & INDEX \\
\hline Untrained $(30 \mathrm{~cm})$ & 0.42 & 1.00 & 1.00 \\
\hline Parkour $(30 \mathrm{~cm})$ & 0.45 & 0.54 & 0.06 \\
\hline Untrained $(60 \mathrm{~cm})$ & 0.45 & 1.00 & 1.00 \\
\hline Parkour $(60 \mathrm{~cm})$ & 0.41 & 0.59 & 0.05 \\
\hline
\end{tabular}

Table 1 Assessment parameters

There was a significant difference of the A-P GRF $(\mathrm{p}<0.0002)$ and CoP surface $(\mathrm{p}<0.0001)$ in the population factor. No significant difference was observed with the height factor: $\operatorname{CoP}(\mathrm{p}<0.45)$ and AP GRF $(\mathrm{p}<0.48)$.

\section{Conclusions}

Parkour practitioners showed a significant better postural control performance than untrained people when executing precision landings. Applications of this technique in daily activities and sports should be studied carefully. The study of parkour techniques will help to understand and better exploit human capabilities. Our future work will be focused on the application of these techniques to anthropomorphic systems motion generation using the robotic framework.

\section{References}

Colby, S. M., Hintermeister, R. a, Torry, M. R., \& Steadman, J. R. (1999). Lower limb stability with ACL impairment. The Journal of Orthopaedic and Sports Physical Therapy, 29(8), 444-451; discussion 452-454. doi:10.2519/jospt.1999.29.8.444

Hrysomallis, C. (2011). Balance ability and athletic performance. Sports Medicine (Auckland, N.Z.), 41(3), 221-32. doi:10.2165/11538560000000000-00000

Takagi, A., Fujimura, E., \& Suehiro, S. (1985). A new method of statokinesigram area measurement. Application of a statistically calculated ellipse. In: Igarashi M, Black FO (eds) Vestibular and visual control of posture and locomotor equilibrium. Kager, Basel, pp 74-79.

Wikstrom, E. a., Tillman, M. D., Smith, A. N., \& Borsa, P. a. (2005). A new force-plate technology measure of dynamic postural stability: The dynamic postural stability index. Journal of Athletic Training, 40(4), 305-309. 